\title{
WORKFLOWS FOR CONDITION INSPECTION DOCUMENTATION OF ARCHITECTURAL HERITAGE BASED ON HBIM: TAKING THREE DUTY ROOMS IN FORBIDDEN CITY OF BEIJING AS AN EXAMPLE
}

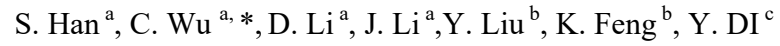 \\ a School of Architecture, Tianjin University, 92 Weijin Rd, Tianjin 300072, China601214045@qq.com, wucong@tju.edu.cn, \\ 790806480@qq.com,908127045@qq.com \\ ${ }^{\mathrm{b}}$ Tianjin University Research Institute of Architectural Design, 192 Anshan West Rd, Tianjin 300073, China (734758540, \\ 364798439)@qq.com \\ c The Palace Museum, 4 Jingshan Qianjie, Beijing 100009, China, zycdyj@163.com
}

\section{Commission II}

KEY WORDS: HBIM, Condition Inspection, Dual-route Workflows, Information Management, Interactive Model, Defects Keynote Dictionary

\begin{abstract}
This paper explores the BIM-based route map and workflows for documentation of condition inspection for architectural heritage, exemplified by an on-going conservation project of three Duty Rooms in Yangxin Hall complex in the Forbidden City, Beijing. Since intensive, multi-disciplinary inspection work for architectural heritage will result in huge amount and categories of data and information, the 2D-based traditional way of documentation is abandoned, while HBIM was introduced for information management and presentation. In respond to multi-disciplinary collaboration, a duel-route workflow is specially developed for the combination of BIM and non-BIM teams, in which the BIM team is responsible for BIM models' creation and maintenance, and for information management and presentation, while the non-BIM team carry out the survey and inspection in their own established way without any requirements for BIM skills, making a little adjustment where necessary, with interactive models as links between them. The practice following the workflows mentioned in this paper proves that condition inspection based on HBIM is applicable, compatible and flexible, providing the possibility to improve the traceability and sustainability of heritage information, and to generate visualized, thematic and integrated presentation in high efficiency and consistency. This paper also provides some solutions to the specific problems encountered during actual operation. For example, the defects keynote dictionary offers a sound tie between the BIM team and non-BIM team, and between site survey and final presentation; the application of shadow elements helps to improve the information management between whole and parts, ideal and actual, 2D and 3D.
\end{abstract}

\section{INTRODUCTION}

\subsection{Background}

The building complex of Yangxin Hall (Hall of Mental Cultivation) used to a very importance residence for the emperors from the $18^{\text {th }}$ to early $20^{\text {th }}$ century within the Forbidden City, Beijing (Figure 1) (Fu 1983; He 2016). Since 2015, a conservation and restoration project has been carried out for this building group. It attaches much importance to the critical process, and multi-disciplinary, in-depth survey, inspection, analysis, research, assessment and documentation are highly required (Shan 2016). As a phrasal result of the ongoing project, this paper will focus on the documentation or information management during the building condition inspection process for the three Duty Rooms which could date back to 1750 and were used as the service centre for the emperors' daily life in the front courtyard of the residence complex (Figure 2). As an integral part of the complex, they are unique and valuable for their roles of spatial transition and construction flexibility, in spite of their relatively modest appearances.

Since intensive, multi-disciplinary inspection work will result in huge amount and categories of data and information, the 2Dbased traditional way of documentation is partly abandoned, while HBIM was introduced for information management and presentation expecting to improve data visualization, traceability and sustainability. In this project, the BIM software Autodesk Revit 2016 and A360 are adopted.

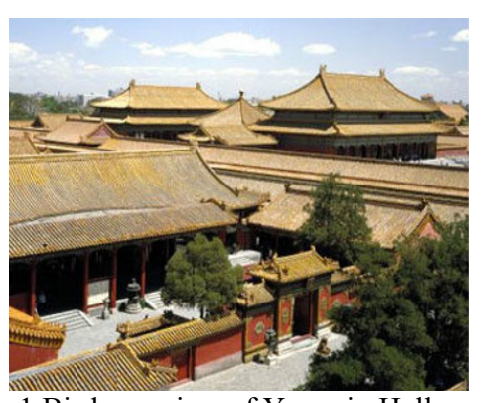

Figure 1 Bird-eye view of Yangxin Hall complex

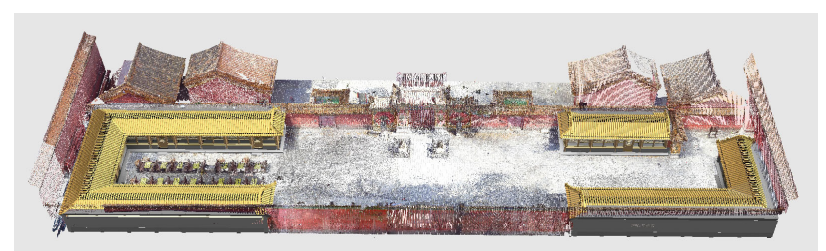

Figure 2 Bird-eye view of the three Duty Rooms (in front, with yellow roofs), mixture of BIM models and point cloud. On the left, upper right and lower right are West, Northeast and Southeast Duty Rooms respectively

\footnotetext{
* Corresponding author
} 


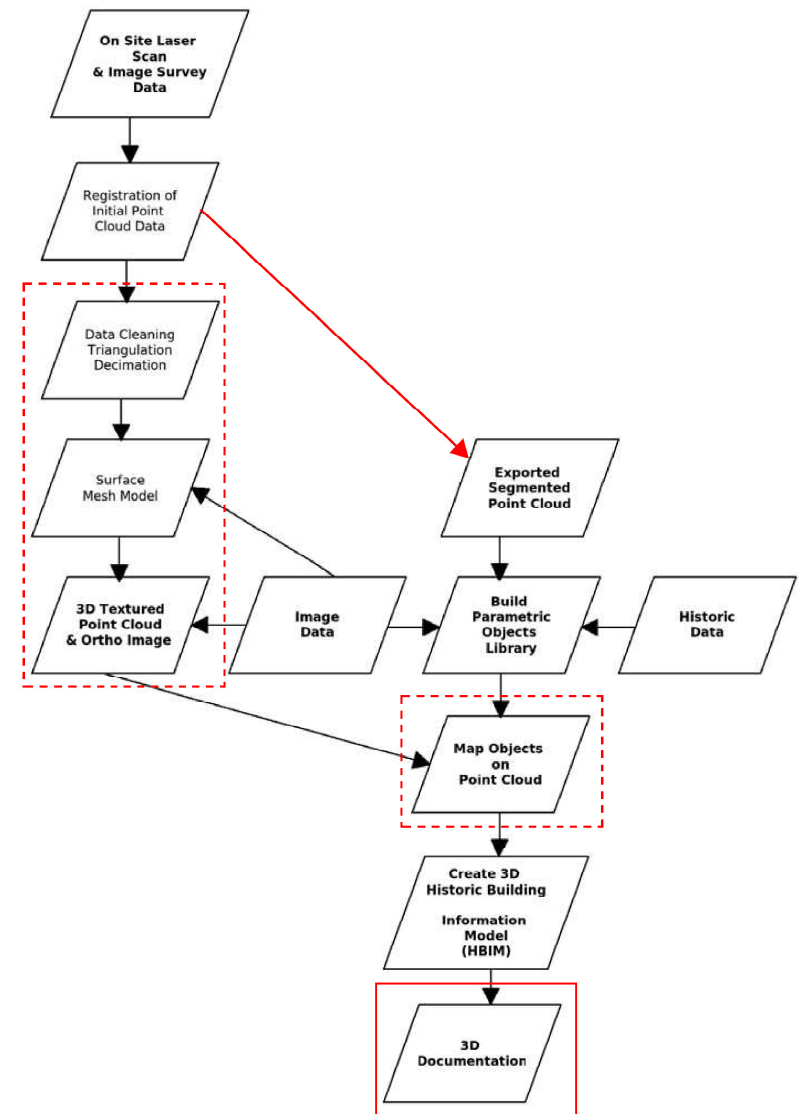

Figure 3 HBIM Workflow by Murphy (2009), marked in red by the authors: the red line with an arrow is a shortcut route, the nodes in dashed rectangles are not necessary, and the final node is supposed to be extended.

In the field of heritage documentation, use of Building information modelling (BIM) is becoming a trend (Logothetis 2015). Murphy (2009) put forward the concept of HBIM and found a way out for point cloud which is difficult to reuse. However, it can be argued that the workflows by Murphy is not applicable. 1) Point cloud is not a necessity for HBIM, but merely one of data resources; 2) When constructing a HBIM model, triangular mesh modelling and texture mapping is not so meaningful; 3) Elements of HBIM should be mapped on the realistic world rather than on the point cloud (Figure 3). In short, HBIM could actually be used just as an index frame of heritage information.

\subsection{Story just Beginning}

In this project, prior to condition inspection or building survey, metric survey including survey control, 3D laser scanning, and hand measurement had been finished and BIM models and measured drawings were prepared. For non-BIM modelling applications, a prepared model means the story is close to an end, but in BIM processing, on the contrary, the story is just beginning. This may be the big difference between BIM and non-BIM modelling. The workflows discussed in this paper actually focus on the process of recording and presenting inspection information based on initially prepared BIM models.

\section{DUEL-ROUTE WORKFLOWS FOR BIM-BASED CONDITION INSPECTION DOCUMENTATION}

\subsection{Collaboration between BIM and Non-BIM Teams}

In respond to multi-disciplinary collaboration, a duel-route workflow is specially developed for the combination of BIM and non-BIM teams, in which the BIM team is responsible for BIM models' creation and maintenance, and for information management and presentation, while the non-BIM team carry out the survey and inspection in their own established way without any requirements for BIM skills, making a little adjustment where necessary to adapt for BIM workflow, with interactive models as links between them (Figure 4).

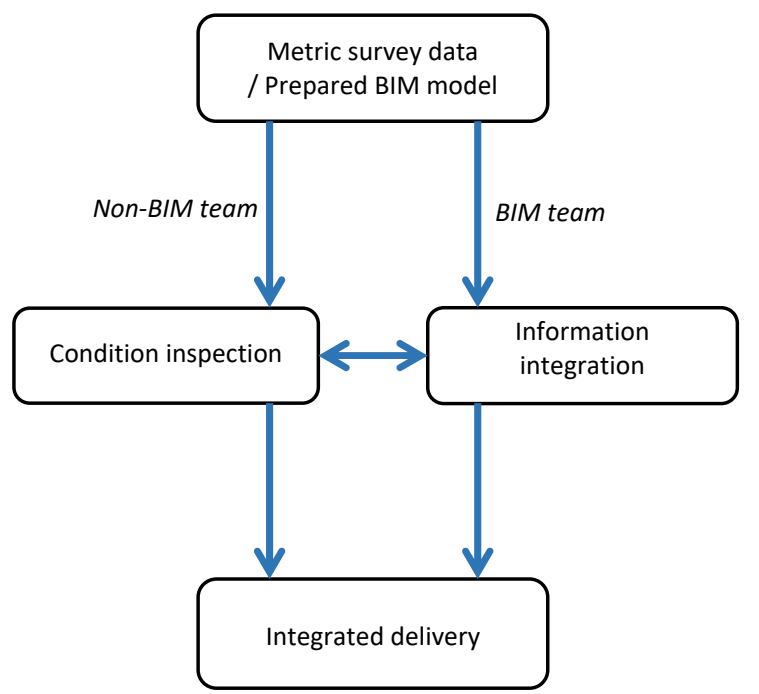

Figure 4 Dual-route workflows

\subsection{BIM Team Workflows}

In general, the workflows for BIM-based inspection documentation can be roughly divided into three phases: modelling, project phasing, information integration and presentation (Figure 5).

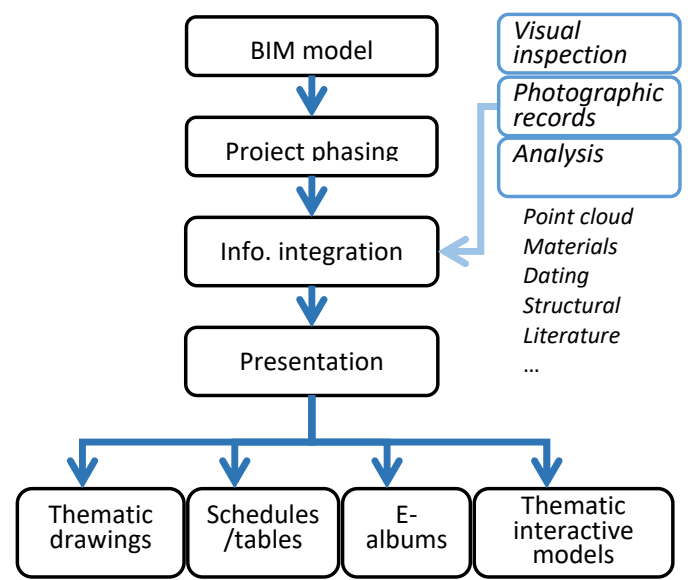

Figure 5 Workflows for BIM team

2.2.1 Modelling: There are too many steps and details about model creation. Since the workflows in question begin with a prepared model, only some important ideas are mentioned here. 1) The model creation is a critical process which requires an informed BIM team who should understand the building surveyed well, and participation in the metric survey is 
preferred. 2) Obviously, in preparing the models, adjustments should be made according to the inspection team's requirement of LOD. In this project, for example, roof tiles are divided into three groups: eaves tiles, ridge tiles and normal tiles to go well with the way of inspection (Figure 6). Similarly, the floor was created as a whole, but divided into many smaller "components", or flooring tiles, to record the information piece by piece. 3) During model preparation, interactive models via A360 was used as the media for proofreading by all participants, from both BIM and non-BIM teams (Figure 7).

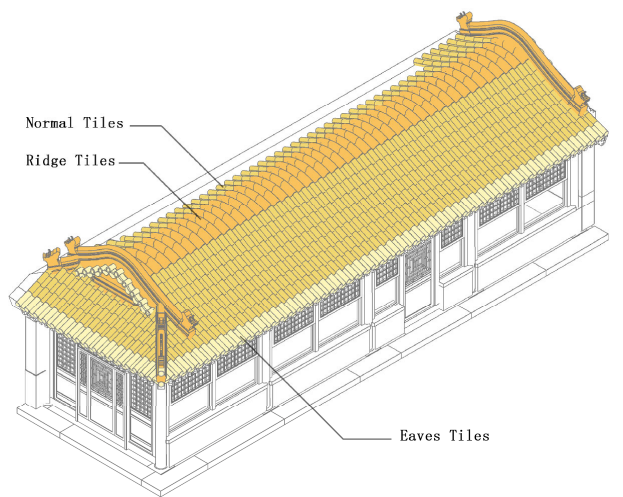

Figure 6 Roofing tiles

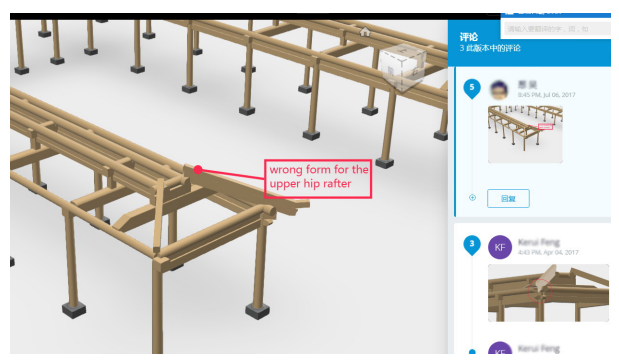

Figure 7 Model proofreading via Autodesk A360

2.2.2 Defining Project Phases: right information should be recorded in right phases. To document the building conditions, a "condition inspection" phase (2016-2017) is established, and prior to it, based on historical archives, there are four phases defined: Qianlong period, prototype, 1950s, and 1980s.

2.2.3 Information Integration: all information or data can be roughly divided into three types: from visual inspection, from photographic records, and from other inspection and analysis, such as deformation analysis from point cloud, material, structural, dating assessment and interpretation of historical literature.

For visual inspection, there are three way of data input: 1) direct input in Revit elements, 2) input in Revit schedules (tables), and 3 ) input and edit in excel files via data export and import. The last one relies on Revit subscriptions such as Revit DB-link and BIM One Export and Import Excel. It is of importance not only because it is a convenient way of batch processing which is quite difficult within Revit, but also it builds a bridge between BIM and non-BIM teams, for using Microsoft excel files or similar editor is close to the latter's routine practice. It is expected to realize the data processing via interactive models in the future work.
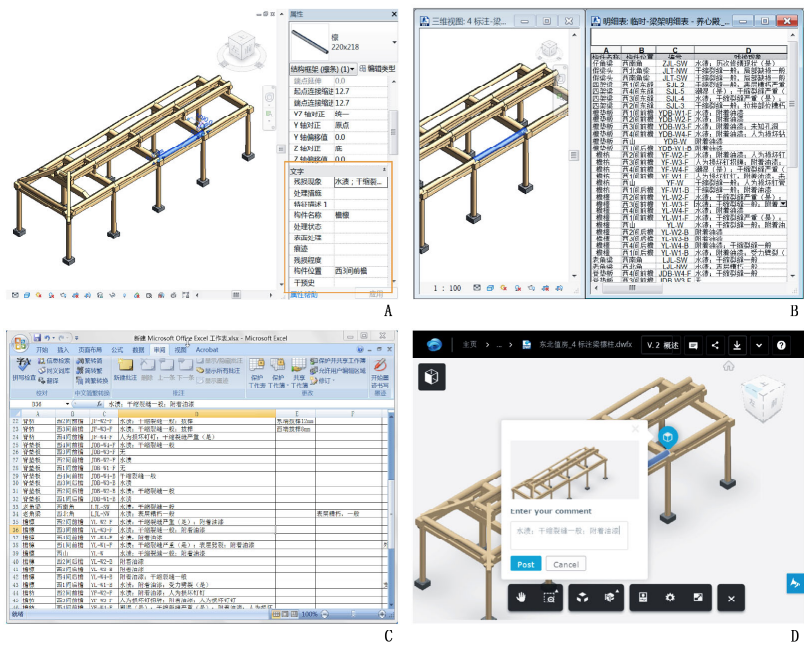

Figure 8 Ways of data input and edit

A) Direct input in Revit; B) input in Revit sheets; C) input and batch processing in Excel with reference to D) an interactive model

For image resources and other quantitative analysis results, the parameters of URL type are used to creation hyperlinks to locate the albums or the original forms of reports.

2.2.4 Presentation and Deliveries: as one of most important characteristics and merits, BIM can provide visualized thematic presentation to make the building and defect information presented in a visualized and logic way.

In this project, views are organized by themes of two levels: firstly, the five building units including platform (foundation if available), timber frames, roof, wall and non-structural woodwork (mainly windows and doors); secondly, the types of defects, for example, rot in wood components, glaze loss of roof tiles, or weathered platform stones.

Subsequently, four types of BIM-based presentation are given: 1) thematic drawings or sheets in Revit, 2) thematic interactive 3D models presented in A360 (Figure 13), 3) schedules, and 4) online or offline e-albums (Figure 14, Figure 15).

Base on a given theme, a typical thematic drawing is actually a combination of $2 \mathrm{D}$ or $3 \mathrm{D}$ drawing, a schedule, photographs selected from the e-albums (Figure 9) or images generated from other analysis software (Figure 11, Figure 12). In a thematic drawing, theme related elements are in different colours which representing certain defects and the degree of damage, while other components are in grey or white as the background.

Consequently, it is feasible for HBIM to provide an integrated deliveries combined with drawings, photographs, tables, interactive models. The improvement is worth of expecting. 


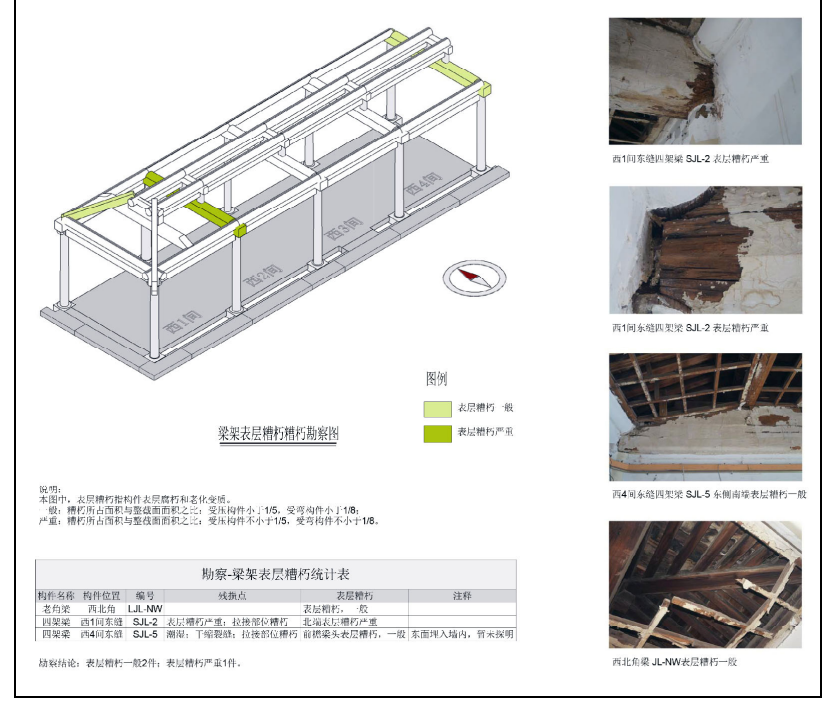

Figure 9 Example of thematic drawings; theme: surface rot of structural wood components

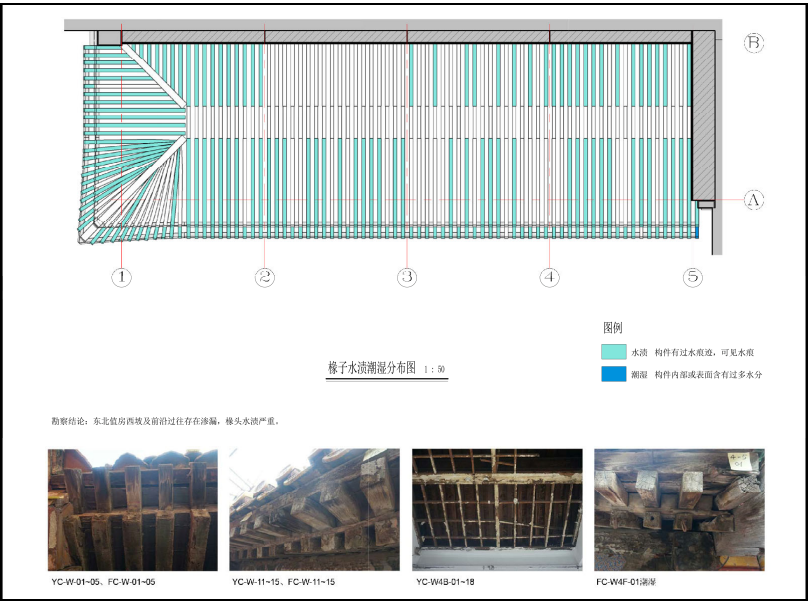

Figure 10 Example of thematic drawings; theme: traces of leakage

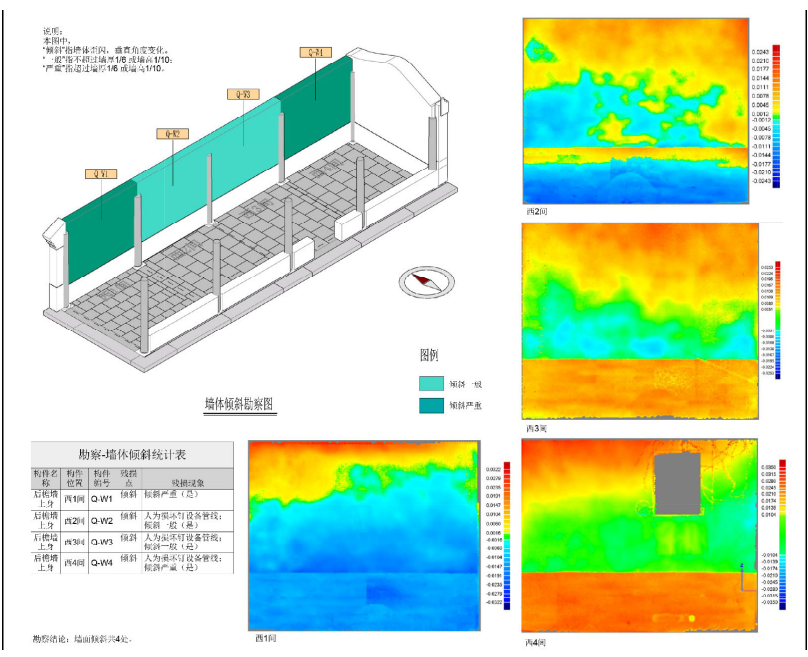

Figure 11 Example of thematic drawings; theme: analysis on the wall surface based on point cloud

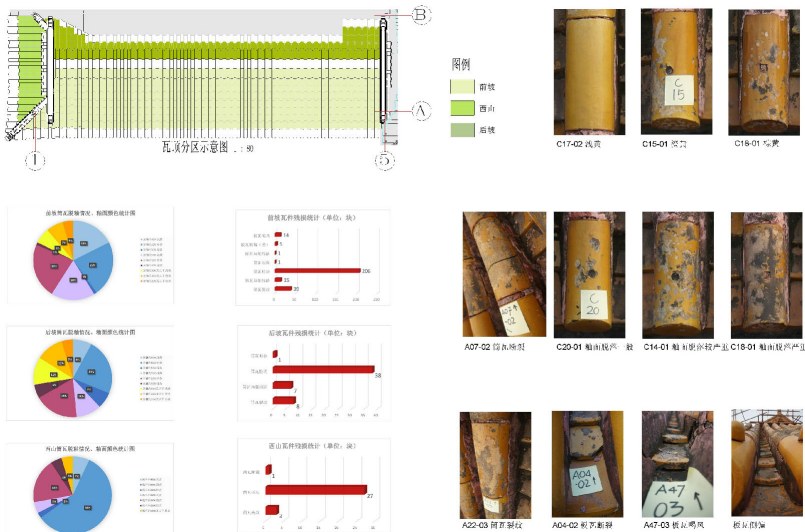

Figure 12 Examples of thematic drawings, theme: regular roofing tiles

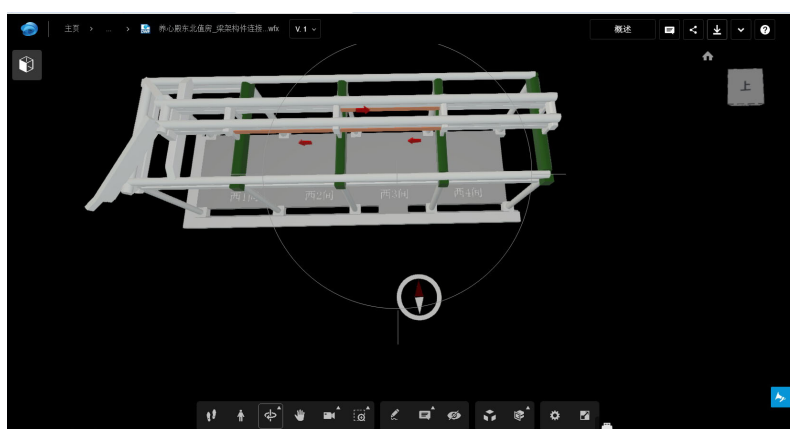

Figure 13 Example of thematic 3D view in A360; theme: problems of structural components joints

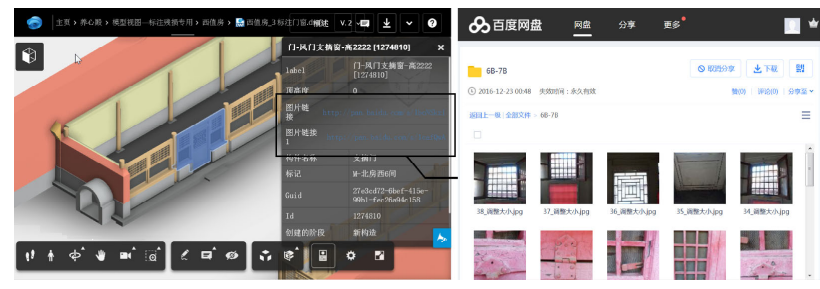

Figure 14 Online e-albums linked with the BIM model

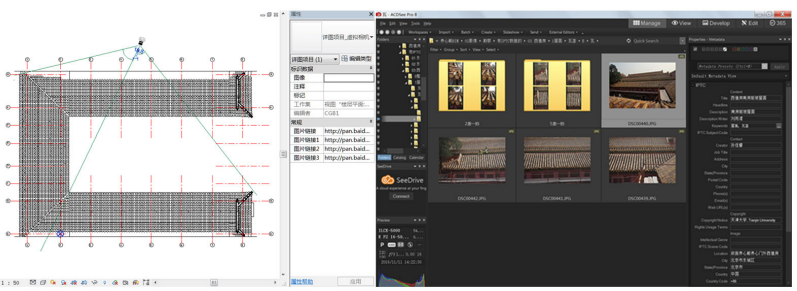

Figure 15 Local e-albums linked with the BIM model

\subsection{Workflow Adjustment for Inspection Teams}

In general, non-BIM inspection teams will just follow their own established workflows, changes only occur in the way of taking on-site survey notes, especially for visual inspection.

Changes in the way of data recording include on-site and offsite aspects:

1) On-site: mark or review on the prepared interactive models in mobile terminal devices (Autodesk A360 is used in the project) (Figure 16); or fill in the hardcopies of blank data 
tables (sheets in Revit) as field record books (survey notes) on occasions when electric devices are unavailable or inconvenient due to poor internet service or bad working conditions (Figure 17).

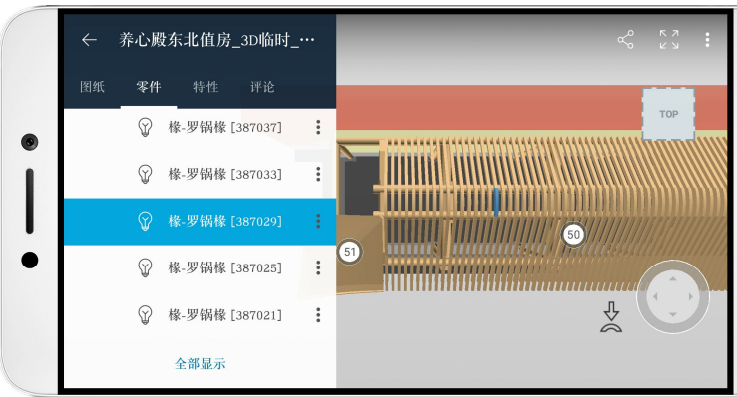

Figure 16 Accessing the interactive models and review it in a mobile phone

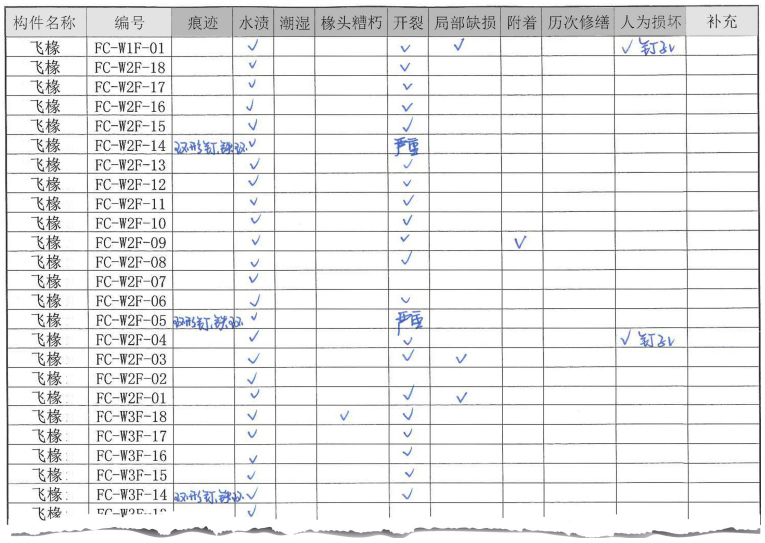

Figure 17 Fill tables exported from BIM file

2) Off-site: record and edit in the excel files exported from the BIM model, with the help of interactive model in A360 (Figure 18)

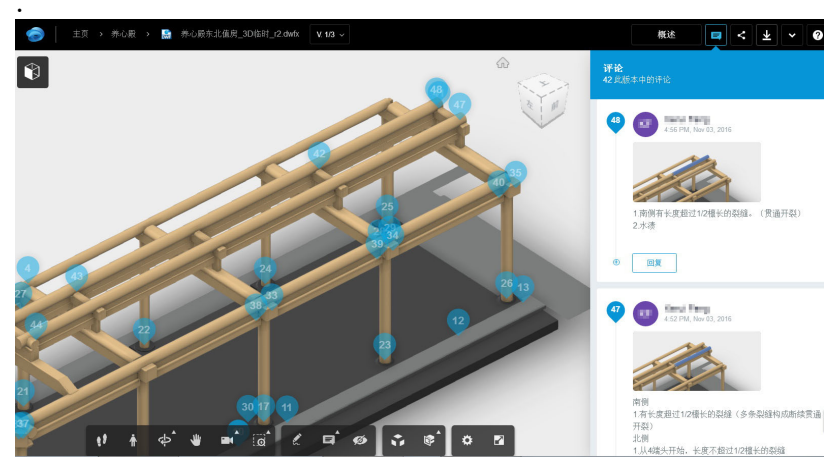

Figure 18 Marks and reviews in A360

In writing final survey reports, all kinds of data-visualized presentation can be explored to get specific conclusions; furthermore, reports itself can be organized by theme modules which are consistent and linked to BIM models (Figure 22).

\section{DIFFICULTIES AND SOLUTIONS}

\subsection{Creating Thematic Drawings}

As mentioned above, Views and drawings are organized by given themes, which can be represented with different graphic display (such as colours, patterns, transparency, line types). With category-based filters, this can be realized by overriding visibility and graphic display to replace elements' original appearance according to their defined materials. However, to define the filters, some specific parameters have to be created in the project file.

3.1.1 Specific Parameters for Visualization and Descriptions: these are the two kinds of parameters in which the former is in the form of numbers, words and phrases to define the graphic display of the elements concerned, while the latter usually is in sentences to give explicit written description (for all differences between them, see Table 1). This configuration guarantees the data-based graphic representation as well as the human readable description in a natural language (Figure 19).

Themes are determined by the categories, amount and distribution of defined defects, so they are relatively flexible and on a case-by-case basis. Usually, combination of relating defects can make up a theme. In this project, for each building unit, the parameter "Defect phenomenon" is used for keynotes, whilst parameters "Defect description" from 1 to 9 are corresponding to nine themes at the most (Figure 20).

Table 1 Comparison between parameters for keynotes and for description

\begin{tabular}{|c|l|l|}
\hline & Parameters for keynotes & $\begin{array}{c}\text { Parameters for } \\
\text { description }\end{array}$ \\
\hline $\begin{array}{c}\text { Symbol } \\
\text { forms }\end{array}$ & Keynotes / keynote values & Natural language \\
\hline $\begin{array}{c}\text { Language } \\
\text { forms }\end{array}$ & $\begin{array}{l}\text { Numbers, words or } \\
\text { phrases }\end{array}$ & $\begin{array}{l}\text { Descriptive } \\
\text { sentences }\end{array}$ \\
\hline Text style & Standard & freely \\
\hline Readers & Machine readable & Human readable \\
\hline Function & $\begin{array}{l}\text { To define the graphic } \\
\text { display of the elements }\end{array}$ & $\begin{array}{l}\text { To give explicit } \\
\text { written description }\end{array}$ \\
\hline
\end{tabular}

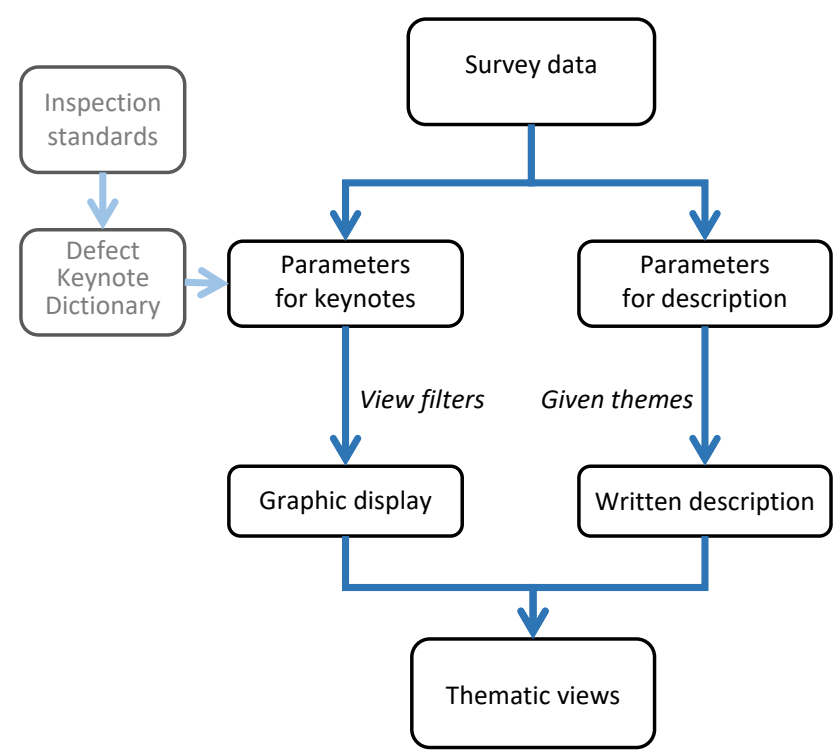

Figure 19 Parameters configuration for thematic drawings 


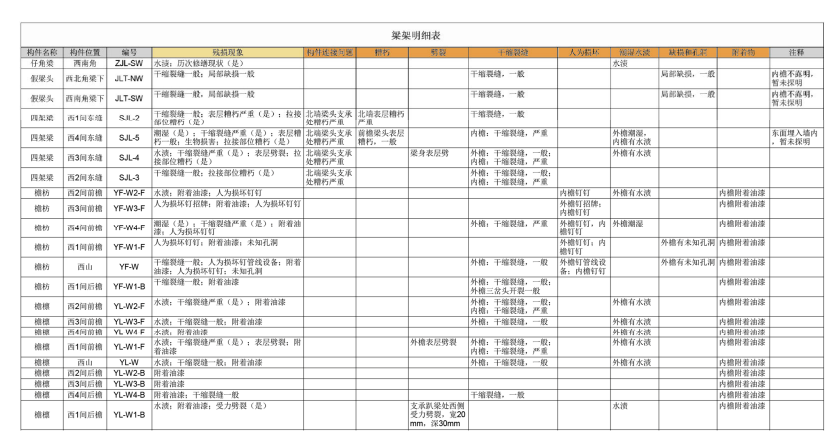

Figure 20 Example of using "Defect phenomenon" (in yellow) and 8 themes of "Defect description" (in orange)

3.1.2 Defects Keynote Dictionary (DKD) are based on and translated from related standards or criteria in enterprise, industrial and national levels. It define the keynote values, keynotes of different defects based on material and techniques, descriptions of the defects, the graphic display in the model views concerned, and so forth (Figure 21). DKD plays a key role in the whole workflows, for it links the inspection operation and the final presentation, and provides the basis to define themes case by case.

\begin{tabular}{|c|c|c|c|c|}
\hline $\begin{array}{l}\text { Keynote } \\
\text { values }\end{array}$ & Keynotes & 部 & 项 & $\begin{array}{l}\text { Legend } \\
\text { (RGB) }\end{array}$ \\
\hline 000001 & 缺失 & 通用 & & $0,70,80$ \\
\hline 000002 & 人为损坏 & 通用 & & $0,71,182$ \\
\hline 000003 & 附着 & 通用 & & $145,115,211$ \\
\hline 000004 & 历次修缮现状 & 通用 & & $217,156,225$ \\
\hline 000005 & 不当修补 & 通用 & & $202,101,209$ \\
\hline 000006 & 不当利用 & 通用 & & $239,64,176$ \\
\hline 010001 & 位移 & 木 & & $225,129,140$ \\
\hline 010002 & 潮湿 & 木 & & $0,146,221$ \\
\hline 010003 & 水渍 & 木 & & $130,230,221$ \\
\hline 010004 & 生物损害 & 木 & & $235,233,195$ \\
\hline 010005 & 局部缺损 & 木 & & / \\
\hline 010005. A1 & 局部缺损, 一般 & 木 & & $208,36,51$ \\
\hline 010005. A2 & 局部缺损, 严重 & 木 & & $137,32,52$ \\
\hline 010006 & 未知孔洞 & 木 & & $97,32,127$ \\
\hline 010101 & 干缩裂缝 & 木 & 檩、梁 & \\
\hline 010101. A1 & 干缩裂㖓, 一般 & 木 & 檩、梁 & $255,95,0$ \\
\hline 010101. A2 & 干缩裂缝, 严重 & 木 & 檩、梁 & $155,77,27$ \\
\hline 010201 & 干缩裂缝 & 木 & 柱 & , \\
\hline
\end{tabular}

Figure 21 Defects Keynote Dictionary

\subsection{Shadow elements}

Sometimes, in Revit models, there is no such objects to represent the units of a building, or some details which cannot be divided from a larger element. However the data or information about them cannot be omitted. To solve the problem, "shadow elements" (shadow family / instance) are devised (LI, S. 2014)

3.2.1 Information for building "units": this includes platform, timber frame, roof, wall, and windows/doors. An "information board" is designed to record the information of the platform.

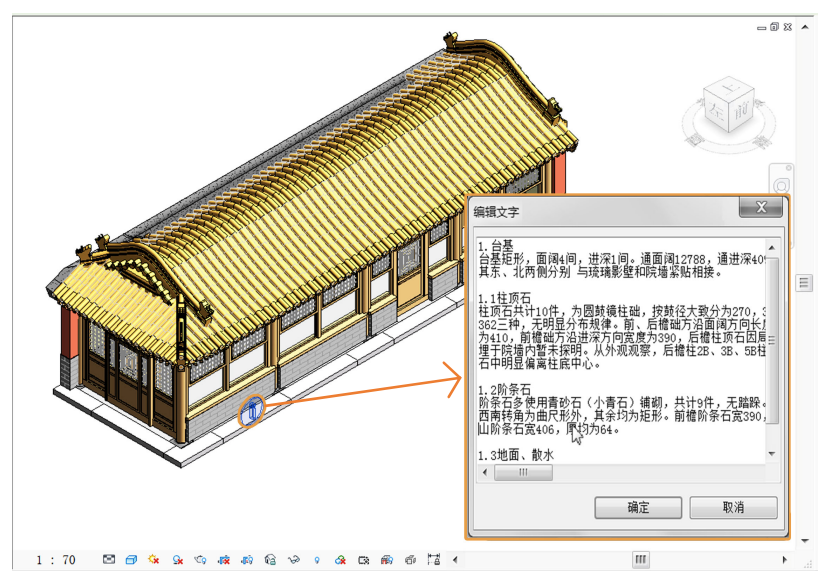

Figure 22 An "information board" is used to record the information of the whole platform

3.2.2 Informatization of 2D drawings: in this case, window and door elements cannot be divided into smaller components, therefore the elevations of the front and back sides seem to be 2D drawings without 3D objects. Here, rectangular "detail components" are used as symbols to represent different components of windows and doors, such as window sills, frames, rails, leafs and sashes (Figure 23).

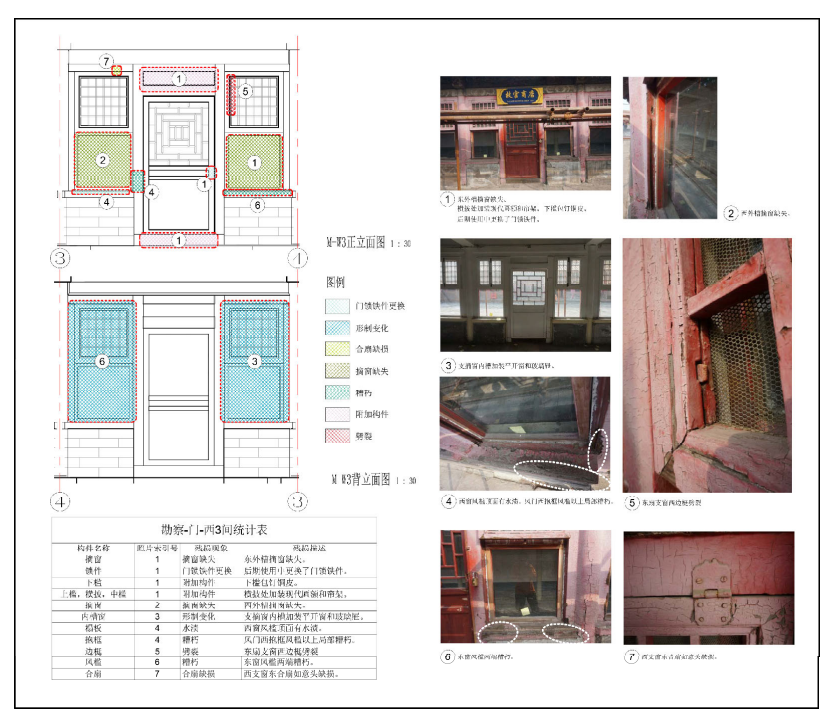

Figure 23 Thematic drawing for windows and doors, with shadow 2D elements

3.2.3 Timber Frame deformation presentation: to represent the slight deformation of the whole timber frame, see Figure 24, another model (in red) is created with deformation sized recollected from point cloud. The deformed model is inserted as a link, so the relation between ideal positions (transparent columns) and realistic positions (columns in red) is possible to be visible. 


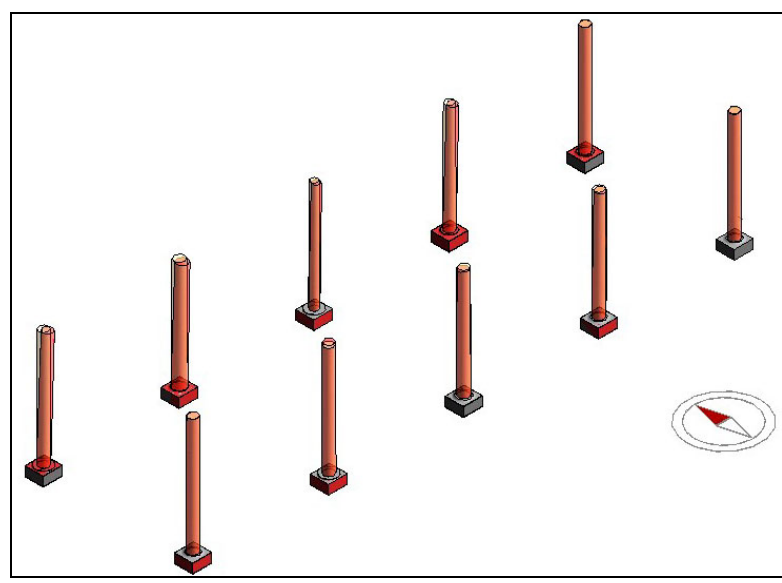

Figure 24 Representation of tilting and settlement of columns via linked shadow elements

\section{CONCULSIONS}

The practice following the workflows mentioned in this paper proves that condition inspection based on HBIM is applicable, compatible and flexible, providing the possibility to improve the traceability and sustainability of heritage information, and to generate visualized, thematic and integrated presentation in high efficiency and consistency.

The dual-route workflows promote collaboration between BIM team and non-BIM team. Surveyors can easily take advantage of HBIM products without mastering BIM skills. This idea can be expected to make BIM more widely accepted in the field of heritage conservation.

This paper provides some solutions to the specific problems encountered during actual operation. For example, the DKD offers a sound tie between the BIM team and non-BIM team, and between site survey and final presentation; the application of shadow elements helps to improve the information management between whole and parts, ideal and actual, and 2D and $3 \mathrm{D}$.

The project proves HBIM is independent from point cloud data, and point cloud is only one of the data resources available.

In the near future, the following works are expected be done:

To develop and refine the dual-route workflow, and make it a computer-aided assessment system in condition inspection. Once building components information are tagged via interactive model, a series of presentation and deliveries would be generated timely. This idea can be extended to practice other than condition inspection.

To develop specific interactive BIM viewer for heritage information management, in which certain data can be edited and updated. It also has the potential to become a platform for export review and public participation.

\section{REFERENCES}

Fu L., Xu Y., 1983, Buildings in the Hall of Mental Cultivation (in Chinese), Forbidden City, (6), pp 4-11
He, B., 2016. The historical development of the Hall of Mental Cultivation (in Chinese). Forbidden City, (12). pp. 52-53.

Li, K., 2015. A study on HBIM-based informatization survey and measurement of Jiayuguan Pass (in Chinese), master dissertation, Tianjin university, Tianjin, China.

Li, S., 2014. A preliminary research about informatization survey and measurement of historical buildings based on BIM technology: under the background of informatization survey and measurement (in Chinese), master dissertation, Tianjin university, Tianjin, China.

Logothetis, S., Delinasiou, A., Stylianidis E., 2015, Building information modelling for cultural heritage: a review, ISPRS Annals of the Photogrammetry, Remote Sensing and Spatial Information Sciences, Volume II-5/W3, 25th International CIPA Symposium 2015, 31 August - 4 September 2015, Taipei, Taiwan. pp. $177-183$

Murphy, M., McGovern E., et al. 2009. Historic building information modelling (HBIM). Structural Survey, 27 (4). pp. 311-327.

Shan J., 2016, Thoughts on instituting researchful protection of the ancient architecture of Palace Museum, Forbidden City, (12). pp. 4-28. 